\title{
The effectiveness of vitamin $D$ supplementation in functional outcome and quality of life (QoL) of lumbar spinal stenosis (LSS) requiring surgery
}

Sangbong Ko ${ }^{*^{*}}$, Seungbum Chae ${ }^{1}$, Wonkee Choi ${ }^{1}$, Jaibum Kwon ${ }^{1}$ and Je-Yong Choi ${ }^{2}$

\begin{abstract}
Study design: This is a retrospective cohort comparative study.

Background: Vitamin D supplementation is considered to be associated with good functional outcome. Thus, a few studies have proposed vitamin D supplementation is benefit to the functional outcome in LSS requiring surgery. The purpose of this study is to identify the prevalence of vitamin D deficiency in patients with LSS requiring surgery, and to compare the differences between the cases whether vitamin $D$ is supplemented and vitamin D is not supplemented in terms of a QoL during postoperative 2 year.

Methods: All patients with LSS who underwent surgery from March 1, 2015 to August 31, 2016 were enrolled. Among them, 61 patients with vitamin D deficiency were divided into two groups (supplemented group (A) and non-supplemented group (B)). Functional outcomes using Oswestry Disability Index (ODI) and Rolland Morris Disability Index (RMDQ) and QoL using SF-36 were evaluated at 12-month and 24-month follow-up periods. Differences in functional score and SF-36 between the vitamin D supplemented and non-supplemented group were compared.

Results: Among the total 102 patients, 78 patients (76.5\%) had vitamin D deficiency. Of the 78 patients, 61 patients were included, 27 patients were group A and 27 patients were group B. There was no difference in age and 25OHD level between the two groups (all $0>0.05$ ). Group $A$ were better functional outcomes at 2 years after surgery $(p<0.05)$. On the QoL, group A were higher score than group B from 12 month later after surgery $(p<0.05)$.

Conclusions: Vitamin D deficiency was highly prevalent in LSS patients (76.5\%). Assessment of serum 25hydroxyvitamin $\mathrm{D}(25(\mathrm{OH}) \mathrm{D})$ is recommended in LSS needing surgical intervention and active treatment vitamin $\mathrm{D}$ supplementation and maintenance of normal range should be considered for better postoperative functional outcome and QoL.
\end{abstract}

Keywords: Lumbar spine, Spinal Stenosis, Surgery, Vitamin D, Functional Outcome, Quality of Life

* Correspondence: bong@cu.ac.kr

'Department of Orthopaedic Surgery, College of Medicine, Daegu Catholic

University, Duryugongwon-ro 17-gil, Nam-gu, Daegu city, Korea

Full list of author information is available at the end of the article

C The Author(s). 2020 Open Access This article is licensed under a Creative Commons Attribution 4.0 International License, which permits use, sharing, adaptation, distribution and reproduction in any medium or format, as long as you give appropriate credit to the original author(s) and the source, provide a link to the Creative Commons licence, and indicate if changes were made. The images or other third party material in this article are included in the article's Creative Commons licence, unless indicated otherwise in a credit line to the material. If material is not included in the article's Creative Commons licence and your intended use is not permitted by statutory regulation or exceeds the permitted use, you will need to obtain permission directly from the copyright holder. To view a copy of this licence, visit http://creativecommons.org/licenses/by/4.0/. The Creative Commons Public Domain Dedication waiver (http://creativecommons.org/publicdomain/zero/1.0/) applies to the data made available in this article, unless otherwise stated in a credit line to the data. 


\section{Background}

Vitamin D plays a role of maintaining the extracellular calcium ion level, which plays an important role in various signaling pathways related to musculoskeletal function [1]. In addition, supplementation of vitamin D has the effect to prevent bone fracture by affecting bone mineralization [2], and has been proven to prevent falls by improving muscle functions [3]. Whereas it has been reported that vitamin $\mathrm{D}$ is effective in the prevention of chronic diseases such as cancer, osteoarthritis, diabetes, and cardiovascular diseases recently [4], the authors do believe that the role of vitamin $\mathrm{D}$ deficiency may have been somewhat neglected by the scientific literature in the past decades, shifting to the extreme opposite of considering vitamin D supplementation the "panacea" which may solve every illness also seems quite irrational. Since the 1980s, it is said that sunlight induces skin cancer and promotes aging, so many people do indoor activities and use a sunscreen during outdoor activities, gradually increasing the vitamin D deficiency and causing vitamin D-related diseases such as rickets and osteomalacia [5]. Studies have recently revealed that more than half of the world's population is experiencing vitamin D deficiency [6] and that vitamin D's importance is re-emphasized by studies that have examined the effects of vitamin D on calcium homeostasis, prevention, and treatment of bone related diseases such as osteoporosis. It is a current trend in the USA and various countries to increase the recommended amount of vitamin D intake.

LSS is a disease with increasing prevalence mainly due to aging. It usually accompanies lower leg radiating pain (LLRP) and low back pain (LBP) and neurogenic claudication. Although there has been a study of the prevalence of vitamin D deficiency in patients with $\operatorname{LSS}[7,8]$, there has not been any study on the prevalence of vitamin D deficiency in patients with severe LSS requiring surgery and any study on the evaluation of postoperative functional outcome measures designed to estimate pain and QoL after supplementation of vitamin D for patients of vitamin D deficiency.

The purpose of this study is to study the prevalence of vitamin D deficiency in patients with LSS who require surgery, and to compare the differences between the case where vitamin D is supplemented for patients with LSS who require surgery and the case where vitamin D is not supplemented for patients with LSS who require surgery in terms of a functional outcome and a QoL.

\section{Methods}

\section{Patient population}

After obtaining approval from our Institutional Review Board (IRB) (approval number: CR-19-110), informed consent was waived from all participants. The vitamin D level of all the 102 patients who underwent surgery for
LSS from March 1, 2015 to August 31, 2016 was investigated. The sample size showing power of 0.8 , effect size of 0.91 , and $\alpha$ error of 0.05 with ODI score difference of $15 \%$ was 20 for each group. Thus 40 subjects were needed for this study. The target patients were those who had chief complaints of lower leg radiating pain as well as neurogenic claudication associated with LBP and referred buttock pain. For these patients, surgery (decompression without fusion) by a spinal specialist was decided, as they showed the findings of spinal canal stenosis (midsagittal diameter of less than $12 \mathrm{~mm}$ ), no foraminal stenosis, no instability via magnetic resonance imaging (MRI), the LSS not being successfully treated by conservative measures.

Of the 78 patients with vitamin D deficiency, 61 patients eligible for inclusion and exclusion criteria (Table 1) were divided into two groups-one group (called group A) who take vitamin $\mathrm{D}$ themselves and the other group (called group B) who do not take vitamin D themselves at a ratio of 1:1. Patients in group A take an intramuscular injection of 100,000 IU of vitamin D3 (D3BASE, ABIOGEN Pharma $\mathrm{SpA}$, Italy) (group A) themselves but, patients in group $\mathrm{B}$ do not take vitamin D supplementation. Patients in both groups were informed of the side effects of the Vitamin D injection (headache, weakness, asthenia, muscle aches,

\section{Table 1 Inclusion and exclusion criteria}

Inclusion criteria

$1 \quad$ Patients with at least one lumbar spinal stenosis (midsagittal diameter of less than $12 \mathrm{~mm}$ ) on MRI

2 Patients who do not have other abnormal findings of the spine (infection, fracture, tumor, etc.)

3 Patients who fully understood this study and voluntarily agreed to the written consent

4 Vitamin D deficiency group

5 Patients who underwent decompression without fusion

Exclusion criteria

1 Patients taking more than $800 \mathrm{IU}$ of vitamin $\mathrm{D}_{3}$ daily

2 Patients with serum calcium level greater than or equal to $10.5 \mathrm{mg} / \mathrm{dl}$

3 Patients with hypercalciuria (spot urine calcium/creatinine ratio $>0.4$ )

4 Patients with malabsorption disease, lymphoma, sarcoidosis, tuberculosis, hyperparathyroidism, and celiac disease

5 Patients with Kidney stone or renal function (GFR $<30 \mathrm{ml} / \mathrm{min} / 1.73 \mathrm{~m}^{2}$ )

6 Patients with a problem with hepatic function

$7 \quad$ Patients with fasting blood sugar (> $126 \mathrm{mg} / \mathrm{dl}$ )

8 Patients who received spinal surgery in the past

9 A patient with a medication contraindicated

10 Patients with lower extremity fractures or vertebral fractures within the past year

11 Patients with psychiatric problems such as depression

12 Patients with gait problems due to other medical problems

$M R I$ : magnetic resonance imaging, GFR glomerular filtration rate 
anorexia, weight loss, nausea, vomiting, and constipation, etc.) and signed an agreement. All patients showed improved LBP, LLRP, and claudication compared to preoperative symptoms with statistically after surgery. So, visual analogue scale (VAS) for LBP, LLRP, and claudication was not performed.

\section{Functional outcome and QoL evaluation}

The functional evaluation for the two randomly divided groups was the validated Korean version of the ODI (version 2.0) and the RMDQ having a score range of zero to 100 . The functional evaluation was performed in the aid of the trained clinical research coordinator at 12 months and 24 months postoperatively. In addition, SF36 questionnaire, a tool for assessing QoL, was filled out by the patient himself with the help of the same coordinator at 12 months and 24 months postoperatively.

\section{Measurement and supplementation of 25(OH)D}

Blood samples were collected between 8:00 am and 8:30 am with patients under fasting condition, in order to reduce errors in circadian variation. Serum 25(OH)D was measured by chemiluminescence immunoassay (LIASON-XL, DiaSorin, Inc., Stillwater, Minnesota, USA). Serum 25(OH)D levels below $20 \mathrm{ng} / \mathrm{ml}(50 \mathrm{nmol} / \mathrm{L})$ were indicated as deficient; $21-29 \mathrm{ng} / \mathrm{ml}$ as insufficient; and above $30 \mathrm{ng} / \mathrm{ml}(75 \mathrm{nmol} / \mathrm{L})$ as normal [9]. In both groups, $5 \mathrm{mg}$ of limaprost-alpha-cyclodextrin clathrate (Opalmon Tab, Dong-A ST, Seoul, Korea) was administered orally three times a day, and the medication was adjusted accordingly the degree of claudication.

\section{Statistical analysis}

Differences in functional score and SF-36 between the vitamin D supplemented and non-supplemented group were compared using a Mann Whitney $U$ test. The statistical analysis was performed using the SPSS software version 19.0 for windows (SPSS, IBM Corporation, Armonk, NY, USA). We considered $p \leq 0.05$ as statistically significant. In addition, between-group differences in terms of VAS scores and functional outcomes were analyzed using Mann-Whitney $U$ test, the power of result in the VAS score difference and functional outcome was determined with $\mathrm{G}$ power 3.1.

\section{Results}

\section{Epidemiological results}

The average age of 102 patients (34 males, 68 females) was $68.26 \pm 9.25$ years. The average age of patients with vitamin D deficiency (a total of 78, 27 male and 51 female) was $68.94 \pm 9.04$ years, and the average age of patients without vitamin D deficiency (a total of 61, 23 male and 31 female) was $68.88 \pm 8.42$ years. There was no statistical significance between the two groups ( $p=$
0.715). Out of the group of vitamin $\mathrm{D}$ deficiency, the average age of the group A (total 27, 11 male and $16 \mathrm{fe}$ male) was $69.44 \pm 2.56$ years, and the average age of the group B (total 27, 12 male and 15 female) was $68.47 \pm$ 2.42 years. There was no statistical significance between the two groups $(p=0.764)$. The average $25(\mathrm{OH}) \mathrm{D}$ result of 78 patients with $25(\mathrm{OH}) \mathrm{D}$ deficiency was $12.87 \pm 4.41$ (range, 4.07 to 19.5$)$. The preoperative average $25(\mathrm{OH}) \mathrm{D}$ values were $10.44 \pm 1.02$ in group $\mathrm{A}$ and $10.97 \pm 1.00$ in group B, respectively, and there was no statistical significance $(p=0.657)$ (Table 2$)$. The postoperative average $25(\mathrm{OH}) \mathrm{D}$ values were $31.23 \pm 1.09$ in group $\mathrm{A}$ and 16.24 \pm 3.21 in group $\mathrm{B}$ at postoperative 12 months, and 32.14 \pm 2.12 in group $A$ and $17.29 \pm 4.38$ in group B at postoperative 24 months, respectively, and there were statistical significance $(p<0.05)$ (Table 2$)$.

\section{Results of functional outcome and QoL}

The preoperative ODI was $59.88 \pm 4.06$ in group $\mathrm{A}$ and $57.65 \pm 3.31$ in group $\mathrm{B}$, showing no statistically significant difference $(p=0.683)$. The preoperative RMDQ was $14.75 \pm 1.07$ in group A and $15.18 \pm 0.84$ in group $\mathrm{B}$, showing no statistical significant difference $(p=$ 0.683). The ODI after 12 months from the surgery was $22.00 \pm 2.70$ in group $\mathrm{A}$ and $28.12 \pm 2.10$ in group $\mathrm{B}$, showing statistical significant difference $(p=0.034)$. The RMDQ was $6.06 \pm 0.86$ in group $A$ and $7.71 \pm 0.95$ in group $\mathrm{B}$, having no difference $(p=0.217)$. The ODI after 24 months from the surgery was $11.00 \pm 1.52$ in group $A$ and $20.94 \pm 1.86$ in group $B$, indicating a better result in group A $(p=0.0002)$. The RMDQ was $3.06 \pm 0.38$ in group $\mathrm{A}$ and $4.94 \pm 0.82$ in group $\mathrm{B}$, indicating a better result in group A $(p=0.110)$ (Table 3$)$.

As for the QoL using SF-36 questionnaire, preoperative mental component score (MCS) was $38.19 \pm 3.49$ in group $A$ and $29.71 \pm 4.53$ in group $B$, showing no statistical significant difference $(p=0.136)$. Preoperative physical component score (PCS) was $30.90 \pm 3.20$ in group A and $26.12 \pm 3.66$ in group $B$, showing no statistical significant difference $(p=0.168)$. MCS after 12 months from the surgery was $63.71 \pm 5.38$ in group A and 43.17 \pm 4.79 in group $\mathrm{B}$. The PCS of the same period was $60.27 \pm 5.11$ in group $A$ and $36.95 \pm 4.42$ in group $B$, indicating that A group shows better MCS and PCS results $(p=0.005, \mathrm{p}=0.001)$. The MCS after 24 months from the surgery was $82.61 \pm 2.19$ in group A, $52.06 \pm 5.43$ in group $\mathrm{B}$, and the PCS of the same period was $70.05 \pm$ 3.41 in group $A$ and $51.65 \pm 4.64$ in group B, respectively. The results of MCS and PCS were better in group A $(p<0.005)($ Table 4$)$.

\section{Discussion}

Jacques et al. [10] asserted that homebound elderly persons who have no specific disease and stay at home have 
Table 2 Epidemiological results

\begin{tabular}{|c|c|c|c|c|}
\hline & Vitamin D non-deficient & Vitamin D deficient & & $p$ value \\
\hline \multirow[t]{3}{*}{ Number of patients (male/female) } & \multirow[t]{3}{*}{$24(7 / 17)$} & $78(27 / 51)$ & & \\
\hline & & Group A & Group B & \\
\hline & & $27(11 / 16)$ & $27(12 / 15)$ & \\
\hline \multirow[t]{3}{*}{ Average age } & \multirow[t]{3}{*}{$68.88 \pm 8.42$} & $68.94 \pm 9.04$ & & 0.715 \\
\hline & & Group A & Group B & \\
\hline & & & $68.47 \pm 2.42$ & 0.764 \\
\hline 25(OH)D (preoperative) & & $10.44 \pm 1.02$ & $10.97 \pm 1.00$ & 0.657 \\
\hline 25(OH)D (postop. 12 month) & & $31.23 \pm 1.09$ & $16.24 \pm 3.21$ & $0.002^{*}$ \\
\hline 25(OH)D (ostop. 24 month) & & $32.14 \pm 2.12$ & $17.29 \pm 4.38$ & $0.003^{*}$ \\
\hline \multirow[t]{3}{*}{ Level of surgery } & L3-4 & 1 & 1 & \\
\hline & $\llcorner 4-5$ & 21 & 20 & \\
\hline & L5-6 & 5 & 6 & \\
\hline
\end{tabular}

25(OH)D 25-hydroxyvitamin D, Postop. postoperative

*Statistically significant with $p<0.05$

high prevalence of vitamin D deficiency and thus, vitamin D supplementation is required. Kim et al. [8] reported a high prevalence of vitamin $\mathrm{D}$ deficiency in elderly patients who find substantial difficulties to go outside due to claudication attributable from LSS. Therefore, they said that even supplementation of vitamin D alone can maintain a stable health status by increasing muscle strength to some extent and keeping balance of muscle strength $[3,11]$, and Bischoff-Ferrari [12] stated that vitamin D supplementation would reduce the falling accidents of the elderly by about $22 \%$.

Although healthy adults are not deficient through sufficient meals and sunlight, others are recommended that $25(\mathrm{OH}) \mathrm{D}$ level in serum maintains $20 \mathrm{ng} / \mathrm{ml}$ or more. However, Tangpricha et al. [13] reported that vitamin D deficiency occurs even in healthy young adults; $11 \%$ in summer and $26 \%$ in winter. Kim et al. [8] reported that the elderly patients with LSS showed increasing prevalence of vitamin D deficiency, and about $74.3 \%$ of them had vitamin $\mathrm{D}$ deficiency. The authors of this paper also stated that a prevalence of $76.5 \%$ (78/102 patients) was exhibited in patients with LSS who require surgery. The authors supposed the cause of vitamin D deficiency was the walking problems due to intermittent neurogenic claudication, and then restriction of going out, but did not make an accurate investigation.
For patients with LSS, surgical treatment has better results than palliative treatment in terms of physical function, pain, and QoL [14]. As described by Kim et al. [7], decompression surgery for patients with LSS showed elevated vitamin D levels, and after 1 year, the levels increased from 11.1 to $14.2 \mathrm{ng} / \mathrm{ml}$ in the depletion group and 23.2 to $23.1 \mathrm{ng} / \mathrm{ml}$ in deficiency group, but neither of the two groups recovered normal levels. The authors of this paper believed that vitamin D supplementation for the vitamin $\mathrm{D}$ deficient group before surgery would be reasonable, and concluded that supplementation of vitamin $\mathrm{D}$ for the vitamin $\mathrm{D}$ deficient group before surgery would result in better functional result of spine and improve QoL.

In our results, ODI after 12 month surgery was improved in vitamin D supplementation group. RMDQ was not different between preoperative and all postoperative periods. However, both SF-36 MCS and SF-36 PCS improved in vitamin D supplementation group from 12 month after surgery. Although there is a growing body of literature suggesting a possible negative influence of preoperative vitamin D deficiency upon surgical outcomes in spine surgery, the vast majority of the literature focuses on the causative link between vitamin D deficiency and pseudoarthrosis [15] or new vertebral fractures [16].

Table 3 Result of functional outcome

\begin{tabular}{|c|c|c|c|c|c|c|}
\hline & \multicolumn{2}{|l|}{ ODI } & \multirow[t]{2}{*}{$p$ value } & \multicolumn{2}{|l|}{ RMDQ } & \multirow[t]{2}{*}{$p$ value } \\
\hline & Group A & Group B & & Group A & Group B & \\
\hline Preoperative & $59.88 \pm 4.06$ & $57.65 \pm 3.31$ & 0.683 & $14.75 \pm 1.07$ & $15.18 \pm 0.84$ & 0.683 \\
\hline 12 month & $22.00 \pm 2.70$ & $28.12 \pm 2.10$ & $0.034^{*}$ & $6.06 \pm 0.86$ & $7.71 \pm 0.95$ & 0.217 \\
\hline 24 month & $11.00 \pm 1.52$ & $20.94 \pm 1.86$ & $0.0002^{*}$ & $3.06 \pm 0.38$ & $4.94 \pm 0.82$ & 0.110 \\
\hline
\end{tabular}

ODI Oswestry Disability Index, RMDQ Rolland-Morris Disability Questionnaire

*Statistically significant with $p<0.05$ 
Table 4 Result of QoL

\begin{tabular}{|c|c|c|c|c|c|c|}
\hline & \multicolumn{2}{|l|}{ SF-36 MCS } & \multirow[t]{2}{*}{$p$ value } & \multicolumn{2}{|l|}{ SF-36 PCS } & \multirow[t]{2}{*}{$p$ value } \\
\hline & Group A & Group B & & Group A & Group B & \\
\hline Preoperative & $38.19 \pm 3.49$ & $29.71 \pm 4.53$ & 0.136 & $30.90 \pm 3.20$ & $26.12 \pm 3.66$ & 0.168 \\
\hline 12 month & $63.71 \pm 5.38$ & $43.17 \pm 4.79$ & $0.005^{*}$ & $60.27 \pm 5.11$ & $36.95 \pm 4.42$ & $0.001^{*}$ \\
\hline 24 month & $82.61 \pm 2.19$ & $52.06 \pm 5.43$ & $<0.005^{*}$ & $70.05 \pm 3.41$ & $51.65 \pm 4.64$ & $<0.005$ \\
\hline
\end{tabular}

MCS mental component score, PCS physical component score

*Statistically significant with $p<0.05$

The effect of vitamin D on the functional outcome and QoL of patients with LSS has not been elucidated but may be deduced from several studies. There is much debate about the pain relief effect of Vitamin D. Although it is a study of idiopathic chronic LBP, Cannell et al. [17] have reported on the pain relief effect of vitamin D. Helde-Frankling et al. [18] have commented on the pain reducing effect of Vitamin D, Cakar et al. [19] said that in a cohort of 149 patients, the authors found that serum vitamin D concentration was not associated with knee pain in patients with osteoarthritis, and Heuch et al. [20] said that after analyzing a data set including 1685 individuals with LBP and 3137 controls without LBP, the authors found no association between vitamin $\mathrm{D}$ status and risk of LBP. In addition, it appears that vitamin D may have an effect to enhance mood, but there are not sufficient studies regarding accurate mechanism [21]. The results of this study showed that both ODI and the QoL after 12 months were improved. In this regard, supplementation of vitamin $\mathrm{D}$ would improve functional outcome and enhance QoL in a long-term perspective, if the normal level of vitamin $\mathrm{D}$ is maintained. However, authors of this study could not figure out the mechanism.

The limitations of this study are as follows: First, there was a lack of research on socio-demographic characteristics. As Kim et al. [8] pointed out, there was a lack of consideration of level of education [22], season [23] as well as medical comorbidity, urban residence, and sunlight exposure. However, this study evaluated serial changes in the same patient. There was no significant difference in the degree of education level, seasonal exposure, medical comorbidity, urban residence, and sunlight exposure. Second, there are many studies on LSS associated with various chronic diseases such as diabetes, hypertension, chronic obstructive pulmonary disease, and gout, but there has been no study on mutual causal relationship [24]. In addition, several authors have shown that vitamin $\mathrm{D}$ itself has the effect of preventing the deterioration of the physical function of a patient by preventing the chronic disease such as cancer, osteoarthritis, diabetes, and cardiovascular diseases $[4,7$, 25, 26]. This study showed a drawback that errors due to factors related to chronic diseases of patients who needed surgery could not be completely eliminated. Third, only the results of improvement of functionality and QoL were obtained. Fourth, the number of patients in each group was too small (27 patients in group A and 27 patients in group B) to analyze the mechanism and related factors, although this was a randomized method. In addition, there was limited data about how long was vitamin D administrated before surgery and how long did it take to normalize the vitamin D serum levels postoperatively.

\section{Conclusion}

The prevalence of vitamin D deficiency in patients with LSS requiring decompression surgery was $76.5 \%$. Although the increase in vitamin D levels in a certain level may be expected if the gait improves after decompression surgery, it seems necessary to maintain $25(\mathrm{OH}) \mathrm{D}$ level in serum by checking vitamin D deficiency before surgery to enhance functional outcome of spine or improve QoL of a corresponding patient in a long-term perspective.

\section{Abbreviations}

QoL: Quality of life; LSS: Lumbar spinal stenosis; ODI: Oswestry Disability Index; RMDQ: Rolland Morris Disability Index (RMDQ); 25(OH)D: 25hydroxyvitamin D; LLRP: Lower leg radiating pain; LBP: Low back pain; MRI: Magnetic resonance imaging; VAS: Visual analogue scale; MCS: Mental component score; PCS: Physical component score

\section{Acknowledgements}

Not applicable

Authors' contributions

All authors read and approved the final manuscript.

\section{Funding}

Not applicable

\section{Availability of data and materials}

Yes

Ethics approval and consent to participate

IRB Number : CR-19-110

Consent for publication

Yes

Competing interests

The authors declare that they have no competing interests. 


\section{Author details}

'Department of Orthopaedic Surgery, College of Medicine, Daegu Catholic University, Duryugongwon-ro 17-gil, Nam-gu, Daegu city, Korea. ${ }^{2}$ Department of Biochemistry and Cell Biology, Kyungpook National University, Daegu, Korea.

Received: 18 January 2020 Accepted: 10 March 2020

Published online: 24 March 2020

\section{References}

1. Lips P. Vitamin D deficiency and secondary hyperparathyroidism in the elderly: consequences for bone loss and fractures and therapeutic implications. Endocr Rev. 2001:22:477-501.

2. Dawson-Hughes B, Harris SS, Krall EA, et al. Effect of calcium and vitamin D supplementation on bone density in men and women 65 years of age or older. N Engl J Med. 1997;337:670-6.

3. Pfeifer M, Begerow B, Minne HW, et al. Effects of a long-term vitamin D and calcium supplementation on falls and parameters of muscle function in community-dwelling older individuals. Osteoporos Int. 2009;20:315-22.

4. Holick MF. Vitamin D deficiency. N Engl J Med. 2007;357:266-81.

5. Robinson PD, Högler W, Craig ME, et al. The re-emerging burden of rickets: a decade of experience from Syndney. Arch Dis Child. 2006;91:564-8.

6. Holick MF, Chen TC. Vitamin D deficiency: a worldwide problem with health consequences. Am J Clin Nutr. 2008;87:1080S-6S.

7. Kim TH, Yoon JY, Lee BH, et al. Changes in vitamin D status after surgery in female patients with lumbar spinal stenosis and its clinical significance. Spine (Phila Pa 1976). 2012;37:E1326-30.

8. Kim TH, Lee $B H$, Lee HM, et al. Prevalence of vitamin D deficiency in patients with lumbar spinal stenosis and its relationship with pain. Pain Physician. 2013;16:165-76.

9. Rosen CJ. Clinical practice. Vitamin D insufficiency. N Engl J Med. 2011;364: 248-54.

10. Jacques PF, Felson DT, Tucker KL, et al. Plasma 25-hydroxyvitamin D and its determinants in an elderly population sample. Am J Clin Nutr. 1997;66:929-36.

11. Bischoff HA, Stähelin HB, Dick W, et al. Effects of vitamin D and calcium supplementation on falls: a randomized controlled trial. J Bone Miner Res. 2003:18:343-51.

12. Bischoff-Ferrari HA, Dawson-Hughes B, Willett WC, et al. Effect of Vitamin D on falls: a meta-analysis. JAMA. 2004;291:1999-2006.

13. Tangpricha V, Pearce EN, Chen TC, et al. Vitamin D insufficiency among freeliving healthy young adults. Am J Med. 2002;1 12:659-62.

14. Weinstein JN, Tosteson TD, Lurie JD, et al. Surgical versus nonsurgical therapy for lumbar spinal stenosis. N Engl J Med. 2008;358:794-810.

15. Ravindra VM, Godzik J, Dailey AT, et al. Vitamin D levels and 1 year fusion outcomes in elective spine surgery : a prospective observational study. Spine (Phila Pa 1976). 2015:40:1536-41.

16. Zafeiris CP, Lyritis GP, Papaioannou NA, et al. Hypovitaminosis D as a risk factor of subsequent vertebral fractures after kyphoplasty. Spine J. 2012;12: 304-12.

17. Cannell JJ, Hollis BW, Zasloff M, et al. Diagnosis and treatment of vitamin D deficiency. Expert Opin Pharmacother. 2008;9:1-12.

18. Helde-Frankling M, Björkhem-Bergman L. Vitamin D in pain management. Int J Mol Sci. 2017;18:E2170.

19. Cakar M, Ayanoglu S, Cabuk H, et al. Association between vitamin D concentrations and knee pain in patients with osteoarthritis. Peer J. 2018;6: e4670.

20. Heuch I, Heuch I, Hagen K, et al. Is there an association between vitamin D status and risk of chronic low back pain? A nested case-control analysis in the Nord-Trøndelag Health Study. BMJ Open. 2017:7:e018521.

21. Lansdowne AT, Provost SC. Vitamin D enhances mood in healthy subjects during winter. Psychopharmacology (Berl). 1998:135:319-23.

22. Choi HS, Oh HJ, Choi H, et al. Vitamin D insufficiency in Korea-a greater threat to younger generation: the Korea National Health and Nutrition Examination Survey (KNHANES) 2008. J Clin Endocrinol Metab. 2008;96: 643-51.

23. Isaia G, Giorgino R, Rini GB, et al. Prevalence of hypovitaminosis D in elderly women in Italy: clinical consequences and risk factors. Osteoporos Int. 2003; 14:577-82.

24. Mahmud T, Basu D, Dyson P. Crystal arthropathy of the lumbar spine: a series of six cases and a review of the literature. J Bone Joint Surg Br. 2005; 87:513-7.
25. Garland C, Shekelle RB, Barrett-Connor E, et al. Dietary vitamin D and calcium and risk of colorectal cancer: a 19-year prospective study in men. Lancet. 1985;1:307-9.

26. Maniar RN, Patil AM, Maniar AR, et al. Effect of preoperative vitamin D levels on functional performance after total knee arthroplasty. Clin Orthop Surg. 2016;8:153-6.

\section{Publisher's Note}

Springer Nature remains neutral with regard to jurisdictional claims in published maps and institutional affiliations.
Ready to submit your research? Choose BMC and benefit from:

- fast, convenient online submission

- thorough peer review by experienced researchers in your field

- rapid publication on acceptance

- support for research data, including large and complex data types

- gold Open Access which fosters wider collaboration and increased citations

- maximum visibility for your research: over $100 \mathrm{M}$ website views per year

At BMC, research is always in progress.

Learn more biomedcentral.com/submissions 